\title{
CFD ANALYSIS OF PULVERIZED COAL COMBUSTION IN A BLAST FURNACE TUYERE: COMPARISON BETWEEN WSGG AND GG MODELS FOR RADIATION MODELING
}

\begin{abstract}
C. V. da Silva ${ }^{a}$,
G. Weber ${ }^{\mathrm{a}}$,

F. R. Centeno ${ }^{\mathrm{b}}$, and F. H. R. França

${ }^{\text {a }}$ Universidade Regional Integrada do Alto Uruguai e das Missões Departamento de Engenharia Mecânica

Av. Sete de Setembro, 1621 CEP 99700-000, Erechim, RS, Brasil cristiano@uricer.edu.br ${ }^{\mathrm{b}}$ Universidade Federal do Rio Grande do Sul Departamento Interdisciplinar em Ciência e Tecnologia' Tramandaí, RS, Brasil

${ }^{c}$ Universidade Federal do Rio Grande do Sul Departamento de Engenharia Mecânica Porto Alegre, RS, Brasil

Received: June 13, 2016

\section{ABSTRACT}

Combustion processes are being employed for many years, and remains a major source of energy for industrial operations through the conversion of chemical energy in thermal energy, besides being usually accompanied by formation of pollutants. This work presents a numerical investigation using the software Ansys CFX to model the process of combustion of pulverized coal injected into a blast furnace for production of pig iron making a comparison between WSGG and GG spectral models for gas radiation aim to verify the influence on the radiation heat transfer and the temperature field. Since global coal reserves are being constantly reduced, new techniques using coal are being studied. Among some effective techniques, there is the injection of pulverized coal through a tuyere installed at the bottom of the blast furnace. Thus, among the objectives of this work is to obtain information about the pulverized coal burning process injected. Firstly, it will be employed a North American coal as a base case in order to better understand the involved phenomena. Simulations were made using the actual operating conditions of a blast furnace, which uses atmospheric air enriched with oxygen for burning the coal. The same boundary conditions and operation of other investigations were considered in order to validate the model developed for this work, and so that it can be applied in similar situations, either in assessments or in projects of coal injection systems and combustion in blast furnaces. The results include temperature and velocity fields, oxygen concentration, and the formation of $\mathrm{CO}$ and $\mathrm{CO} 2$ and they are in agreement with data from literature. Comparing the results of this study with the results obtained in the work (Gu et al., 2010) It observed a qualitative similarity between them and also quantitative. Furthermore, it was found that, in this case, modeling the absorption spectrum of the combustion gases resulting in changes in flame form, but did not significantly alter the magnitude of temperatures, since the walls of the equipment are considered adiabatic.
\end{abstract}

Revised: July 30, 2016 Accepted: September 27, 2016
Keywords: blast furnace, pulverized coal injection, tuyere, numerical simulation, CFX

\section{NOMENCLATURE}

$A_{c} \quad$ pre-exponential factor of coal Arrhenius equation

C carbon

$\mathrm{CO}$ carbon monoxide

$\mathrm{CO}_{2}$ carbon dioxide

$C_{O} \quad$ raw coal mass fraction, $\mathrm{kg} / \mathrm{kg}$

$C_{c h} \quad$ char mass fraction, $\mathrm{kg} / \mathrm{kg}$

$\mathrm{CH}_{4}$ methane

$C_{\mu} \quad$ empirical constant of turbulence model

$c_{p} \quad$ and specific heat of the mixture, $\mathrm{kJ} / \mathrm{kg} . \mathrm{K}$

$D_{i} \quad$ kinetic diffusivity, $\mathrm{m}^{2} / \mathrm{s}$

$\tilde{h}$ average enthalpy of the mixture, $\mathrm{kJ} / \mathrm{kg}$

$h_{i}^{0} \quad$ formation enthalpy, $\mathrm{kJ} / \mathrm{kg}$

$\mathrm{H}_{2}$ hydrogen

$\mathrm{H}_{2} \mathrm{O}$ wather

$\overline{M M}_{i}$ mixture molecula mass, $\mathrm{kg} / \mathrm{kmol}$

$\mathrm{N}_{2} \quad$ nitrogen

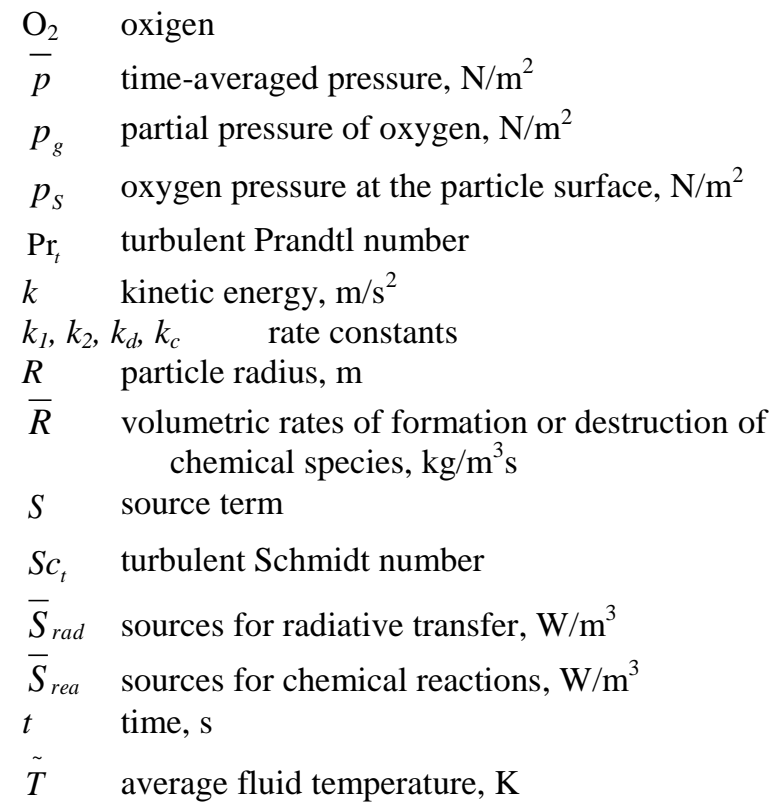


Tc activation temperature of coal Arrhenius equation

$U_{j} \quad$ velocity vector, $\mathrm{m} / \mathrm{s}$

$\tilde{U}_{i j} \quad$ mass-averaged velocity of fluid component $i$, $\mathrm{m} / \mathrm{s}$

$V \quad$ volatiles

$x \quad$ spatial coordinate, $\mathrm{m}$

$\tilde{Y}_{i} \quad$ mass fraction of component $i$ of the mixture, $\mathrm{kg} / \mathrm{kg}$

$Y_{1}, Y_{2}$ taxa of efficiency of devolatilization

\section{Greek symbols}

$\tilde{\rho}_{i} \quad$ mass-average density of fluid component $i$ in the mixture, $\mathrm{kg} / \mathrm{m}^{3}$

$\bar{\rho} \quad$ mass-average density of mixture, $\mathrm{kg} / \mathrm{m}^{3}$

$\mu \quad$ dynamic viscosity, N.s $/ \mathrm{m}^{2}$

$\mu_{t} \quad$ turbulent viscosity, N.s $/ \mathrm{m}^{2}$

$\mu_{\text {eff }} \quad$ effective viscosity, N.s $/ \mathrm{m}^{2}$

$\delta_{i j} \quad$ Krönecker delta function

$\varepsilon \quad$ kinetic energy dissipation, $\mathrm{m} / \mathrm{s}^{3}$

$\varpi \quad$ specific dissipation of kinetic energy, $\mathrm{m} / \mathrm{s}^{3}$

$\kappa$ thermal conductivity of the mixture, $\mathrm{W} / \mathrm{m} . \mathrm{K}$

$\overline{\mathfrak{R}} \quad$ universal ideal gas constant, $\mathrm{kJ} / \mathrm{kg} . \mathrm{K}$

\section{Subscripts}

\section{$H \quad$ energy}

$i \quad$ component $i$ of mixture

$j \quad$ component $j$ of mixture

$k \quad k$-th reaction

$p \quad$ particle

$g \quad$ gas

ref reference

$U$ momentum conservation equation

\section{INTRODUCTION}

It is known that coal plays an important role in the evolution of energy systems and industrial applications. Since the industrial revolution, a considerable amount of coal has been employed for power generation in steam engines (Boubel et al., 1994). In the last decade of the nineteenth century, the pulverized coal began to be used also in the cement industry as fuel for drying ovens (Singer, 1984). There is an estimative that in recent decades, approximately $90 \%$ of all energy generated in the world will be obtained by the combustion process, which explains the growing interest in research these processes (Warnatz et al., 2006).

Pulverized coal has been widely applied in thermoelectric power plants for electricity production (Hinrichs, 2002). On the other way, it is also widely used in Brazilian metallurgical industry for the refining of metals in blast furnaces, which often uses imported coal, due to the low quality of the Brazilian coal that requires a pretreatment specific for each type of manufacturing process. Blast furnaces are used worldwide in the steel industry manufacturing of pig iron. The coal injection has many advantages compared to coke as reduced consumption, increased productivity and also improved control of flame temperature inside the furnace (Guo et al., 2003). However, because of the higher price of coke as compared to pulverized coal, the pulverized coal injection technique with tuyere has been developed for several years to partially replace the coke consumption ( $\mathrm{Du}$ et al., 2006). The tuyere is the device installed at the bottom of the furnace employed to inject the pulverized coal into the blast furnace, as shown in Fig. 1.

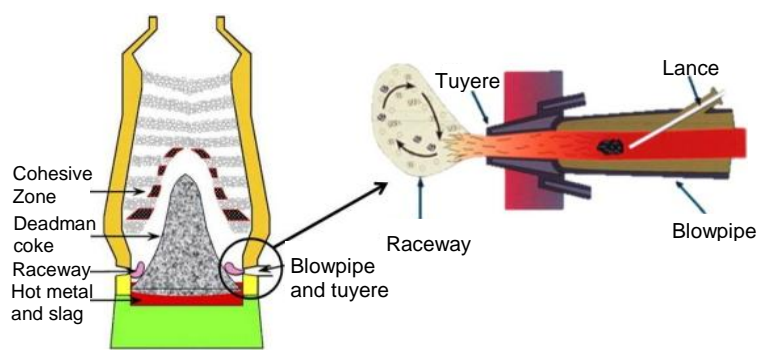

Figure 1. Schematic diagram of the internal structure of a blast furnace.

The blast furnace with a high rate of pulverized coal injection has been recognized as an efficient process for the manufacture of pig iron for reducing costs, as well as to arrive its life time (Ishii, 2000). However, with the growth in the use of pulverized coal, doubts arise related to the choice of which is the best technique to perform the process of coal injection. As a consequence, it is necessary to understand the complex physical and chemical phenomena existing in the injection and burning of pulverized coal. Due to the difficulty in performing measurements in blast furnaces, CFD tool has been considered as a viable technology for obtaining such information and predicting the optimum conditions for coal injection (Du et al., 2006; Chen, 2005).

The process of pulverized coal injection is highly relevant to the performance of the blast furnace to produce pig iron. Many are the works in the literature about this subject (Chen (2005), Guo et al. (2005), Du et al. (2006), Du et al. (2007), Gu et al. (2010), Vascellari et al. (2012), Yeh et al. (2012)), but there aren't any study about the influence of the thermal radiation on the combustion process in this equipment. In this context, the present work aim to evaluate the combustion characteristics of pulverized coal in the fuel injection system (tuyere) in a blast furnace by numerical simulations using the CFD tool, thus seeking to develop and refine the process injection and burning of pulverized coal, validating the model developed for the study. The main goal is 
to evaluate the influence of radiant properties of gas phase making a comparison between WSGG (Weighted-Sum-of-Gray-Gases) and GG (Gray Gas) spectral models in a thermal radiation.

\section{MATHEMATICAL MODELING}

The devolatilisation of coal was modeled using the two-steps Arrhenius rate model (Ubhayakar et al., 1977), in which two different reaction rates and yields devolatilisation compete to produce pyrolysis of the raw coal. As a result, the final yield of devolatilisation depend on the temperature history of the particle, and will increase with temperature, resulting somewhere between $Y_{1}$ and $Y_{2}$. In this model, the mass fraction of raw coal was specified as the mass fraction of volatile substances, since all of these materials can be converted to volatile (Silva, 2007).

It was considered that the combustion occurs at finite rates of chemical reactions in which the devolatilisation of coal occurs in two mechanisms, yielding methane and carbon monoxide as products. For reaction of methane, the WD2 chemical reactions model was used (Westbrook and Drier, 1981). Figure 2 shows diagrammatically the mechanisms of coal devolatização and carbon and volatile substances oxidation.

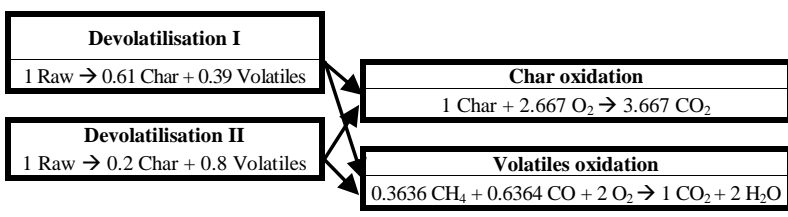

Figure 2. Basic scheme of coal reactions (Ubhayakar, 1977).

A particle of coal consists of raw coal, Co, composed of char, Char, volatiles, moisture and ash. Therefore, after having occurred devolatilisation and drying, the particle becomes composed of char and ash, as shown in Fig. 3.

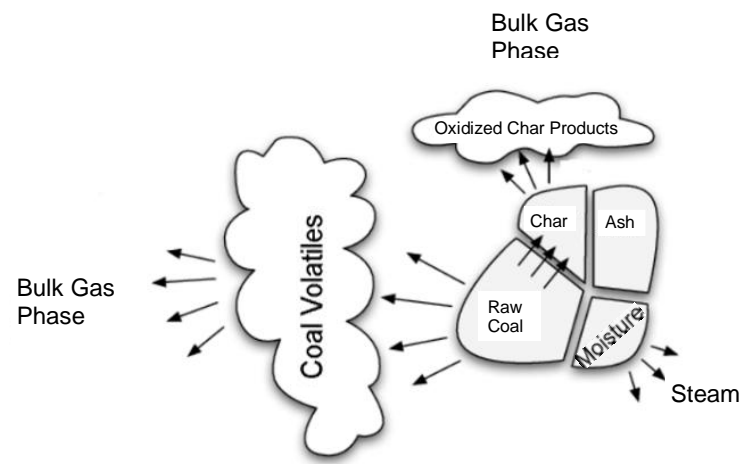

Figure 3. Illustration of coal particle during devolatilisation.

\section{Mass and species conservation}

For a multicomponent fluid, scalar transport equations are solved for velocity, pressure, temperature and other quantities of the fluid. The bulk motion of the fluid is modeled using single velocity, pressure, temperature and turbulence fields. The influence of the multiple components is felt only through property variation by virtue of differing properties for the various components. Each component has its' own equation for conservation of mass. After Favre-averaging this equation can be expressed in tensor notation as

$$
\frac{\partial\left(\tilde{\rho}_{i} \tilde{U}_{j}\right)}{\partial x_{j}}=-\frac{\partial}{\partial x_{j}}\left(\rho_{i}\left(\tilde{U}_{i j}-\tilde{U}_{j}\right)-{\tilde{\rho_{i}}}^{\prime \prime} U_{j}{ }^{\prime \prime}\right)+\bar{S}_{i}
$$

where $\tilde{U}_{j}=\sum\left(\tilde{\rho}_{i} \tilde{U}_{i j}\right) / \bar{\rho} \cdot \tilde{\rho}_{i}$ and $\bar{\rho}$ are the massaverage density of fluid component $i$ in the mixture and average density, respectively, $x$ is the spatial coordinate, $\tilde{U}_{j}$ is the vector of velocity and $\tilde{U}_{i j}$ is the mass-averaged velocity of fluid component $i$. The term $\rho_{i}\left(\tilde{U}_{i j}-\tilde{U}_{j}\right)$ represents the relative mass flow, and $S_{i}$ is the source term for component $i$ which includes the effects of chemical reactions. Note that if all the equations represented by Eq. (1) are added over all components, and the source term is set to zero, the result is the standard continuity equation.

The relative mass flow term accounts for differential motion of the individual components. At this work, this term was modeled for the relative motion of the mixture components and the primary effect is that of concentration gradient. Therefore,

$$
\rho_{i}\left(\tilde{U}_{i j}-\tilde{U}_{j}\right)=-\frac{\rho D_{i}}{\bar{\rho}} \frac{\partial \tilde{\rho}_{i}}{\partial x_{j}}
$$

where $D_{i}$ is the kinetic diffusivity. The mass fraction of component $i$ was defined as

$$
\tilde{Y}_{i}=\frac{\tilde{\rho}}{\bar{\rho}}
$$

Substituting this expressions into Eq. (1) and modeling the turbulent scalar flows using the eddy dissipation assumption it follows that

$$
\frac{\partial}{\partial x_{j}}\left(\bar{\rho} \tilde{U}_{j} \tilde{Y}_{i}\right)=\frac{\partial}{\partial x_{j}}\left(\left(\rho D_{i}+\frac{\mu_{t}}{S c_{t}}\right) \frac{\partial \tilde{Y}_{i}}{\partial x_{j}}\right)+\bar{S}_{i}
$$


where $\mu_{t}$ is the turbulent viscosity and $S c_{t}$ is the turbulent Schmidt number. Note that the sum of component mass fractions over all components is equal to one.

\section{Momentum equation}

For the fluid flow the momentum conservation equations are given by:

$$
\begin{array}{r}
\frac{\partial}{\partial x_{j}}\left(\bar{\rho} \tilde{U}_{i} \tilde{U}_{j}\right)=-\frac{\partial p}{\partial x_{j}} \delta_{i j}+\frac{\partial}{\partial x_{j}}\left(\mu_{e f f} \frac{\partial \tilde{U}_{i}}{\partial x_{j}}\right) \\
+\frac{\partial \tilde{U}}{\partial x_{j} \partial x_{i}}+\bar{S}_{U}
\end{array}
$$

where $\mu_{e f f}=\mu+\mu_{t}$ and $\mu$ is the mixture dynamic viscosity and $\mu_{t}$ is the turbulent viscosity, defined as $\mu_{t}=C_{\mu} \rho k^{2} / \varepsilon$. The term $p^{*}=\bar{p}-(2 / 3) k$ is the modified pressure, $C_{\mu}$ is an empirical constant of the turbulence model and equal to $0.09, \bar{p}$ is the timeaveraged pressure of the gaseous mixture, and $\delta_{i j}$ is the Krönecker delta function. $\bar{S}_{U}$ is the source term, introduced to model the buoyancy and drag force due to the transportation particles, and other mathematical terms due to turbulence models. The Boussinesq model was used to represent the buoyancy force due to density variations. The $k$ - $\varpi$ model were used to provide the turbulence on the flow Wilcox (1988).

\section{Energy conservation}

Considering the transport of energy due to diffusion of each chemical species, the energy equation can be written as

$$
\begin{aligned}
& \frac{\partial}{\partial x_{j}}\left(\bar{\rho} \tilde{U}_{j} \tilde{h}\right)=\frac{\partial}{\partial x_{j}}\left(\kappa \frac{\partial \tilde{T}}{\partial x_{j}}\right)+\bar{S}_{r a d}+\bar{S}_{r e a}+\bar{S}_{T}+ \\
& \frac{\partial}{\partial x_{j}}\left(\sum_{i}^{N c} \tilde{h}_{i}\left(\rho D_{i}+\frac{\mu_{t}}{S c_{t}}\right) \frac{\partial \tilde{Y}_{i}}{\partial x_{j}}+c_{p} \frac{\mu_{t}}{\operatorname{Pr}_{t}} \frac{\partial \tilde{T}}{\partial x_{j}}\right)
\end{aligned}
$$

where $\tilde{h}$ and $c_{p}$ are the average enthalpy and specific heat of the mixture. The latter is given by

$$
c_{p}=\sum_{i} \tilde{Y}_{i} c_{p, i}
$$

where $c_{p, i}$ and $\tilde{Y}_{i}$ are the specific heat and the average mass fraction of the i-th chemical species, $\kappa$ is the thermal conductivity of the mixture, $\operatorname{Pr}_{t}$ is the turbulent Prandtl number, and $\bar{S}_{\text {rad }}, \bar{S}_{\text {rea }}$ and $\bar{S}_{T}$ represent the sources of thermal energy due to the radiative transfer, the chemical reactions and sink our source of energy. The term $\bar{S}_{\text {rea }}$ can be written as:

$$
\bar{S}_{\text {rea }}=\sum_{\alpha}\left[\frac{h_{i}^{0}}{\overline{M M}_{i}}+\int_{\tilde{T}_{r e f, i}}^{\tilde{T}} c_{p, i} d \tilde{T}\right] \bar{R}_{i}
$$

where $\tilde{T}$ is the average temperature of the mixture, $h_{i}^{0}$ and $\tilde{T}_{r e f, i}$ are the formation enthalpy and the reference temperature of the $i$-th chemical species. To complete the model, the density of mixture can be obtained from the ideal gas state equation (Kuo, 1996; Turns, 2000), $\bar{\rho}=p \overline{M M}(\bar{\Re} \tilde{T})^{-1}$, where $p$ is the combustion chamber operational pressure, which is here set equal to $1 \mathrm{~atm}$, and $\overline{M M}$ is the mixture molecular mass. The aforementioned equations are valid only in the turbulent core, where $\mu_{t} \gg \mu$. Close to the wall, the conventional logarithmic law of the wall is used (Nikuradse, 1933).

To consider thermal radiation exchanges inside the combustion chamber, the Discrete Transfer Radiation Model (DTRM) was employed, considering that the scattering is isotropic. The effect of the non-gray gaseous mixture was considered by original WSGG model, using the coefficients obtained by Dorigon et al. (2013). The WSGG model coefficients employed in this work were those for partial pressures of $0.1 \mathrm{~atm}, 0.2 \mathrm{~atm}$ and 0.7 atm for $\mathrm{CO}_{2}, \mathrm{H}_{2} \mathrm{O}$ and $\mathrm{N}_{2}$, respectively, being those values commonly considered for methane-air combustion and while the $\mathrm{N}_{2}$ is considered transparent to radiation, as usual in combustion of fuel gas. The radiative properties required for an entrained particle phase are the absorption coefficients and scattering phase function, which depend on the particle concentration, size distribution, as well as effective complex refractive indices. However, optical properties of coal are not well characterized (Asotani et al., 2008). Generally, as a starting point to arrive at a tractable method for calculating radiative properties, the particles were assumed as spherical and homogeneous. At this work, the heat transfer from gas mixture to particle considers that the particles are opaque bodies with emissivity equal to one (blackbodies), and the Hanz-Marshall correlation was used to model the heat transfer coupling between the gas mixture flow and the particles (Ansys Inc., 2004). In fact, heat transfer to the walls in coal combustion process is mainly due to radiation and the convective heat transfer has only a minor contribution (Xu et al., 2000). 


\section{The E-A (Eddy Breakup - Arrhenius) chemical reactions model}

The reduced chemical reactions model employed in this work assumes finite rate reactions and a steady state turbulent process to volatiles combustion. In addition, it was considered that the combined premixed and non-premixed oxidation occurs in two global chemical reaction steps, and involving only nine species: $\mathrm{O}_{2}, \mathrm{CH}_{4}, \mathrm{~N}_{2}, \mathrm{H}_{2} \mathrm{O}, \mathrm{CO}_{2}, \mathrm{CO}$, NOx, $\mathrm{HCN}$ and HCO. A conservation equation is required for each species but nitrogen. Thus, one has the conservation equation for the $i$-th chemical species, given by Eq. (4), where the source term, $S_{i}$, considers the average volumetric rate of formation or destruction of the $i$-th chemical species at all chemical reactions. This term is computed from the summation of the volumetric rates of formation or destruction in all the $k$-th reaction where the $i$-th species is present, $\overline{R_{i, k}}$. Thus, $\overline{R_{i}}=\sum_{k} \overline{R_{i, k}}$. The rate of formation or destruction, $\overline{R_{i, k}}$, was obtained by a combined Arrhenius-Magnussen model, the EBU-Arrhenius (Eaton et al., 1999). Such relations are appropriate for a wide range of applications, for instance, laminar or turbulent chemical reactions with or without premixing. Such, the rate of formation or destruction of the chemical species was taken as the lowest one between the values obtained from each model. It follows that Silva et al. (2007) used this formulation in this work to simulate the combustion process of methane and air in a cylindrical chamber obtaining good results.

\section{The coal devolatilisation model}

The devolatilisation of the coal was modeled using the generic Arrhenius reactions capability in two steps (Ubhayakar et al., 1977) in which two reactions with different rate parameters and volatiles yields compete to pyrolysis the raw coal. The first reaction dominates at lower particle temperatures and has a yield $Y_{1}$ lower than the yield $Y_{2}$ of the second reaction which dominates at higher temperatures. As a result, the final yields of volatiles will depend on the temperature history of the particle, and will increase with temperature, lying somewhere between $Y_{1}$ and $Y_{2}$. In this model, the mass fraction of the raw coal is specified as the mass fraction of volatiles (here methane and carbon monoxide, see Fig. 1) since all this material could be converted to volatiles. At time $t$, it was assumed that a coal particle consist of mass of raw coal $\left(C_{O}\right)$, of mass of residual char $\left(C_{c h}\right)$, after devolatilisation has occurred, and of mass of ash $(A)$. The rate constants $k_{1}$ and $k_{2}$ of two reactions determine the rate of conversion of the raw coal:

$$
\frac{d C_{O}}{d t}=-\left(k_{1}+k_{2}\right) C_{O}
$$

the rate of volatiles production and the rate of char formation is, respectively, given by

$$
\frac{d V}{d t}=\left(Y_{1} k_{1}+Y_{2} k_{2}\right) C_{O}
$$

and

$$
\frac{d C_{c h}}{d t}=\left(\left(1-Y_{1}\right) k_{1}+\left(1-Y_{2}\right) k_{2}\right) C_{O}
$$

\section{The field char oxidation model}

The oxygen diffusion rate is given by $k_{d}\left(p_{g}-p_{S}\right)$, where $p_{g}$ is the partial pressure of oxygen in the furnace gases far from particle boundary layer and $p_{S}$ is the oxygen pressure at the particle surface. The value of $k_{d}$ is given by $k_{d}=D_{r e f} R_{p}^{-1}\left(T_{p}-\tilde{T}_{g}\left(2 T_{r e f}\right)^{-1}\right)^{\alpha} p_{A} / \bar{p}$, where $R_{p}$ is the particle radius, $T_{p}$ is the particle temperature, $\tilde{T}_{g}$ is the far-field gas temperature, $p_{A}$ is atmospheric pressure, $D_{r e f}$ is the dynamic diffusivity, and $\alpha$ is the exponent with value 0.75 . The char oxidation rate per unit area of particle surface is given by $k_{c} p_{s}$. The chemical rate coefficient is given by, $k_{c}=A_{c} \exp \left(-T_{c} / T_{p}\right)$, where the parameters $A_{c}$ and $T_{c}$ depends on the type of coal. The overall char reaction rate of a particle is given by $\left(k_{d}{ }^{-1}+k_{c}{ }^{-1}\right)^{-1} C_{O_{2}} 4 \pi R_{p}{ }^{2} \bar{p} / p_{A}$, and is controlled by the smallest of the two rates, $k_{d}$ and $k_{c}$.

\section{NUMERICAL METHOD}

To solve the problem presented, the Finite Volume Method (FVM) of (Patankar, 1980) was chosen and commercial software Ansys CFX v. 14.5 simulation platform was adopted. The power law was selected to assess the flows on the surface of the control volume and function up-wind was prescribed for the interpolation scheme. The pressure-velocity coupling was solved by the SIMPLE algorithm (Patankar, 1980). As the conservation equations are nonlinear, relaxation factors were used for all conservation equations and additional models.

\section{PHYSICAL MODEL}

\section{Description geometry}

The geometry of the tuyere can be seen in Fig. 
5. The injection lance is inserted in an axial and concentric form to the center of the product line. The inner diameter of the nozzle is $19 \mathrm{~mm}$. The length of the studied tuyere is $580 \mathrm{~mm}$, having a diameter gradual reduction from $166 \mathrm{~mm}$ (at the inlet) to 150 $\mathrm{mm}$ at $240 \mathrm{~mm}$ from the initiation of the tuyere.

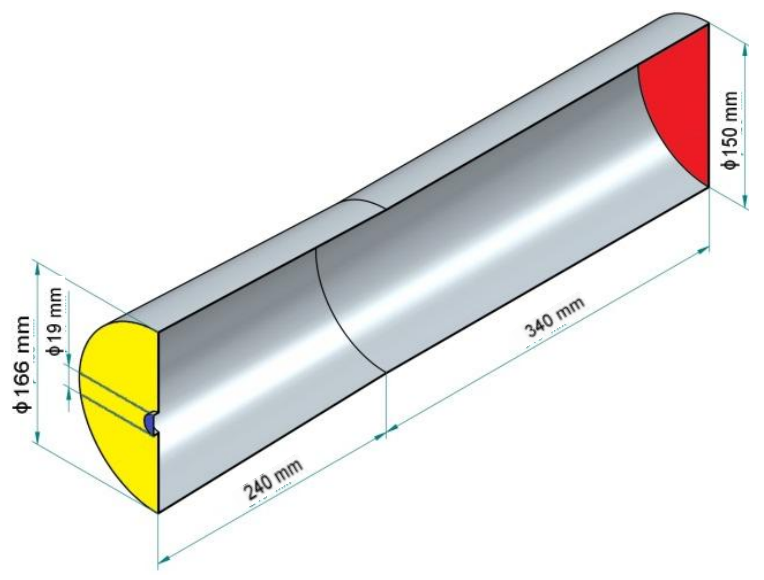

Figure 5. Domain for simulation.

\section{Mesh description}

The domain that is considered includes the entire inner region of the tuyere. The discretization of the grid was performed using tetrahedral volumes. A total of 2.300.000 volumes was considered and each control volume is not greater than $10 \mathrm{~mm}$. Prismatic volumes were used on the wall contour to better capture the flow behavior in that region. Then, four layers of prismatic volumes, with a growth rate of $25 \%$ between layers were introduced on the mesh.

The mesh independence test was conducted to select the best mesh in the experiment for satisfactory results. It is possible to see in Fig. 6 that the curve of results obtained by the mesh number 4 is very similar to the curve of results obtained by the mesh number 5. This approximation of curves on the plot is an evidence that the number of elements present in the mesh is not significantly interfering with the results. Thus, the mesh number 4 was adopted as basis of entire procedure of numerical simulation of this paper.

\section{Operating conditions}

The boundary conditions applied in this study are consistent with those used by (Gu et al., 2010). For this problem, it was considered the adiabatic walls. The features used in the numerical simulation can be found in Tab.1.

Table 1. Parameters of operation.

\begin{tabular}{|c|c|c|c|c|c|}
\hline & Mass flow & Temp. & $\mathrm{N}_{2}$ & $\mathrm{O}_{2}$ & $\mathrm{H}_{2} \mathrm{O}$ \\
\hline Primary Air & $3.09 \mathrm{~kg} / \mathrm{s}$ & $1493 \mathrm{~K}$ & $72 \%$ & $27 \%$ & $1 \%$ \\
\hline Transport Gas & $0.0136 \mathrm{~kg} / \mathrm{s}$ & $360 \mathrm{~K}$ & $100 \%$ & $0 \%$ & $0 \%$ \\
\hline Coal & $0.382 \mathrm{~kg} / \mathrm{s}$ & $320 \mathrm{~K}$ & - & - & - \\
\hline
\end{tabular}

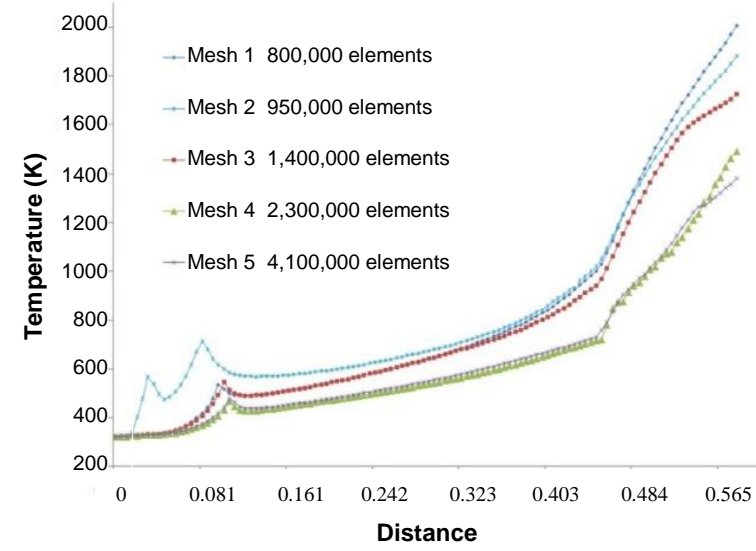

Figure 6. Mesh independence test.

The coal used in the simulations has also its composition extracted from the study of ( $\mathrm{Gu}$ et al., 2010), which was named "Coal A". The property of this type of coal is showing in Tab. 2.

Table 2. Chemical composition of coal (Gu et al., 2010).

\begin{tabular}{|c|c|c|c|c|c|}
\hline \multicolumn{7}{|c|}{ Coal chemical species } \\
\hline $\mathrm{C}$ & $\mathrm{H}_{2}$ & $\mathrm{O}_{2}$ & $\mathrm{~N}_{2}$ & Ash & Moisture \\
\hline $78.76 \%$ & $4.82 \%$ & $4.72 \%$ & $1.67 \%$ & $6.43 \%$ & $3.6 \%$ \\
\hline
\end{tabular}

\section{RESULTS}

The distribution of velocity fields are shown in Fig. 7. In this figure, the results of $\mathrm{Gu}$ et al. (2010) are superimposed in order to compare the results, and validate the modeling applied in the present work. In this work, the comprehensive modeling based on Eulerian system describing the gas-particle flow and coal combustion is used. Mass transfer, heat transfer and motion of gas-particle are described by conservation equations of mass, energy and momentum. The $k-\varepsilon-k_{p}$ two-phase turbulence model is used to model the gas and particle turbulence; gas combustion is determined by the EBU-Arrhenius combustion model, two-competing reaction model is used to calculate the coal devolatilization rate, and the overall reaction rate of char reaction is simulated by diffusion-kinetic model. Radiative heat transfer is calculated by the discreteordinates model, considering the gray gas model. There is a remarkable low velocity zone in the central part of the tuyere and a large increase in speed in the peripheral region of the flame. A low velocity zone is caused by particles of pulverized coal injected with a lower velocity than the oxidizing gas. In the course of combustion of the coal particles, the weight is reduced because the release of volatile particles occurred, thereby causing an increase of its velocity near the outlet region of the tuyere. The combustion also produces an acceleration of oxidizing gas that enters the system at about $120 \mathrm{~m} / \mathrm{s}$ and arrives at the outlet region of $190 \mathrm{~m} / \mathrm{s}$. 
In Fig. 8 it can be seen temperatures fields present in the combustion of pulverized coal injected in a symmetry plane of the tuyere. The data of $\mathrm{Gu}$ et al. (2010) are overlapped in the figure. It was observed that the two simulations showed very similar temperature distributions. As coal is injected at a lower temperature than the temperature of the oxidizing gas, a zone of lower temperature in the central region of the tuyere can be observed. With the heating of coal particle along the path begins to hasten the devolatilisation of coal, which is when the particle leaves the volatile matter of coal. The volatile matter who left the coal is mixed with oxygen at high temperature on site, generates the flame around the particle of coal. This is easily seen in Fig. 8, because a region with temperatures around $2000 \mathrm{~K}$ starts to be generated on the outlet region of the tuyere.

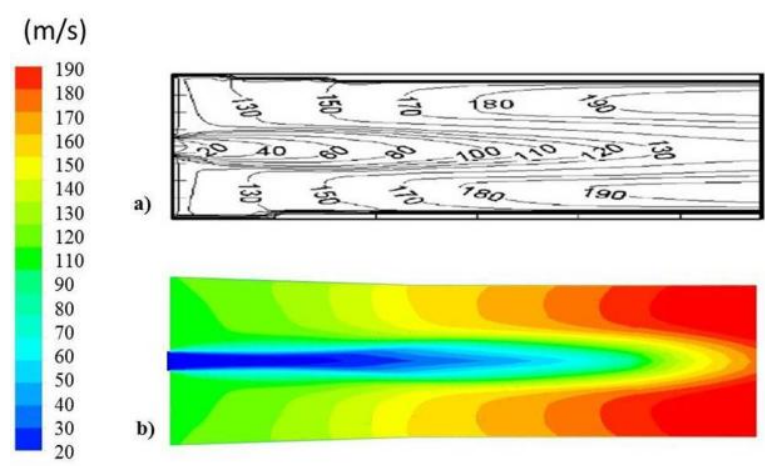

Figure 7. Velocity fields on a transverse plane at the tuyere: (a) results of Gu et al. (2010); (b) Present work using WSGG.

(K)

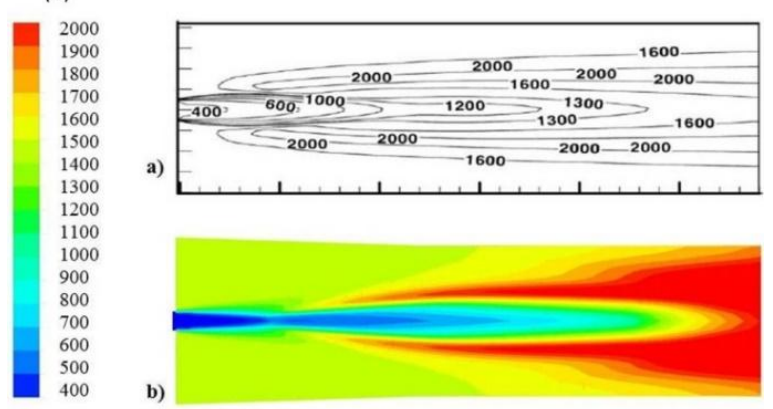

Figure 8. Temperature field on a transverse plane at the tuyere: (a) results of Gu et al. (2010); (b) Present work using GG model.

It is observed that when the coal particle is injected into the tuyere, the combustion is very fast because the volatile material is released, mixed with oxygen, thereby causing the oxygen to be quickly consumed within the flame. Because the blowing speed of the oxidizing gas is approximately $125 \mathrm{~m} / \mathrm{s}$ and considering the small length of the equipment is obtained the particle residence time of about $5 \mathrm{~ms}$, so that a considerable part of the fuel exit the tuyere unburned on the flame.

An important novelty of the present study is the implementation of an updated radiative-property model for thermal radiation calculations of the gaseous phase. The WSGG model, with coefficients developed by Dorigon et al. (2013) is here employed. The WSGG radiation turned the flame more compact and long, as Fig. 9, but did not alter significantly the flame pattern or the rates of chemical reaction, that are governed mainly by turbulence.

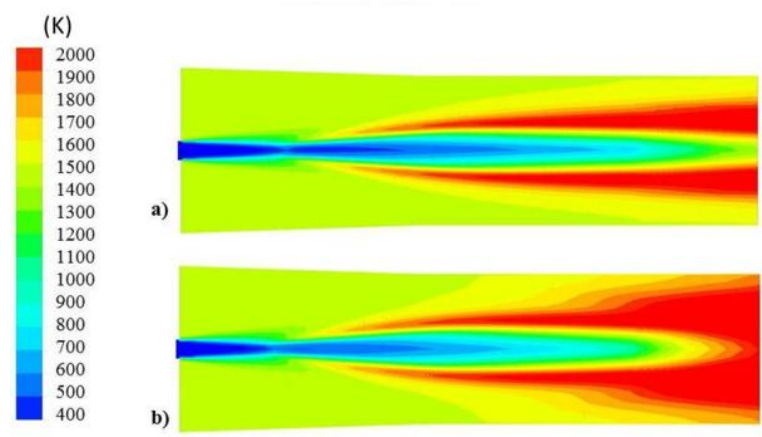

Figure 9. Temperature field: (a) WSGG model; (b) GG model.

\section{CONCLUSIONS}

This work aimed to develop a mathematical model based on mass conservation, chemical species and energy, and the use of compatible finite volume technique for burning pulverized injected coal into a tuyere. Operating conditions and equipment boundary conditions followed the information available in the study of (Gu et al., 2010), who validated their results from comparison with experimental data obtained based on a blast furnace in actual size and full operation, located in East Chicago, USA. Comparing the present results with the results obtained on the paper of $\mathrm{Gu}$ et al. (2010) we observed a qualitative and quantitative similarity between both. Furthermore, it was found that, in this case, the WSGG model for the radiative modelling of the combustion gases resulted in changes to the flame shape, but did not significantly alter the temperatures magnitude, since the equipment walls were found to be adiabatic.

\section{ACKNOWLEDGEMENTS}

The authors thank for the support of $\mathrm{MCT} / \mathrm{CNPq}$ - National Research Council (Brazil).

\section{REFERENCES} Theory.

Ansys Inc., 2004, User's guide - CFX Solver

Asotani, T., Yamashita, T., Tominaga, H., Uesugi, Y., Itaya, Y., and Mori, S., 2008, Prediction of Ignition Behavior in a Tangentially fired 
Pulverized Coal Boiler Using CFD, Fuel, Vol. 87, pp. 482.

Boubel, R. W., Fox, D. L., Turner, D. B., and Stern, A. C., 1994, Fundamentals of Air Pollution, Academic Press, San Diego.

Carvalho, M. G., Farias, T., and Fontes, P., 1991, Predicting Radiative Heat Transfer in Absorbing, Emitting, and Scattering Media Using the Discrete Transfer Method, ASME HTD, Vol. 160, pp. 17-26.

Chen, C. W., 2005, Numerical Analysis for the Multi-Phase Flow of Pulverized Coal Injection Inside Blast Furnace Tuyere, Applied Mathematical Modelling, Vol. 29, pp. 871-884.

Dorigon, L. J., Duciak, G., Brittes, R., Cassol, F., Galarça, M., and França, F. H. R., 2013, WSGG Correlations Based on HITEMP2010 for Computation Ofthermal Radiation in Non-Isothermal, Non-Homogeneous $\mathrm{H}_{2} \mathrm{O} / \mathrm{CO}_{2}$ Mixtures, IJHMT, Vol. 64, pp. 863-873.

Du, S. W., and Chen, W. H., 2006, Numerical Prediction and Practical Improvement of Pulverized Coal Combustion in Blast Furnace, Heat Mass Transfer, Vol. 33, pp. 327-334.

Du, S. W., Chen, W. H., and Lucas, J., 2007, Performances of Pulverized Coal Injection in Blowpipe and Tuyere at Various Operational Conditions, Energy Conversion e Management, Vol. 48, pp. 2069-2076.

Eaton, A. M., Smoot, L. D., Hill, S. C., and Eatough, C. N., 1999, Components, Formulations, Solutions, Evaluations, and Applications of Comprehensive Combustion Models, Progress in Energy and Combustion Science, Vol. 25, pp. 387436.

Freire, A. P. S., Menut, P. P. M., and Su, J., 2002, Turbulência, Vol. 1, Associação Brasileira de Ciências Mecânicas - ABCM, Rio de Janeiro. (in Portuguese)

Gu, M., Chen, G., Zhang, M., Huang, D. F., Chaubal, P., and Zhou, C. Q., 2010, ThreeDimensional Simulation of the Pulverized Coal Combustion Inside Blast Furnace Tuyere, Applying Mathematical Modell, Vol. 34, pp. 3536-3546.

Guo, Y. C., Chan, C. K., and Lau, K. S., 2003, Numerical Studies of Pulverized Coal Combustion in a Tubular Coal Combustor with Slanted Oxygen Jet, Fuel, Vol. 82, pp. 893-907.

Guo, B., Zulli, P., Rogers, H., Mathieson, J. G., and Yu, A., 2005, Three-Dimensional Simulation of Flow and Combustion for Pulverized Coal Injection, ISIJ International, Vol. 45, pp. 1272-1281.

Hinrichs, R. A., and Kleinbach, M., 2002, Energy: Its Use and the Environment, 3rd Edition, Harcourt, Philadelphia.

Hottel, H. C., and Sarofim, A. F., 1967, Radiative Transfer, McGraw-Hill.

Ishii, K., 2000, Advanced Pulverized Coal Injection Technology and Blast Furnace Operation, Pergamon Press, Elsevier Science.
Knudsen, J. G., 1958, Fluid Dynamics and Heat Transfer, Mc Graw Hill.

Kuo, K. K., 1996, Principles of Combustion, John Wiley \& Sons.

Maliska, C.R., 2004, Transferência de Calor e Mecânica dos Fluidos Computacional: Fundamentos e Coordenadas Generalizadas, 2.ed., Livros Técnicos e Científicos. (in Portuguese)

Nikuradse, J., 1933, Strömungsgesetze in rauhen Rohren: aus d. Kaiser-Wilhelm-Inst. Strömungsforschg, Göttingen. of Forschungsheft, Verein Deutscher Ingenieure, VDI-Verlag Edn., Vol. 361, pp. 22.

Patankar, S. V., 1980, Numerical Heat Transfer and Fluid Flow, Hemisphere.

Silva, C. V., França, F. H. R., and Vielmo, H. A., 2007, Analysis of the Turbulent, Non-Premixed Combustion of Natural Gas in a Cylindrical Chamber with and Without Thermal Radiation, Combustion Science and Technology, Vol. 179, pp. 1605-1630.

Singer, S., 1984, Pulverized Coal Combustion: Recent Developments, Noyes Publications.

Turns, S. T., 2000, An Introduction to Combustion - Concepts and Applications, 2nd Edition, McGraw-Hill.

Ubhayakar, S. K., Stickler, D. B., Rosenberg Jr, C. W. V., and Gannon, R. E., 1977, Rapid Devolatilization of Pulverized Coal in Hot Combustion Gases, Symposium International on Combustion, Vol. 16, pp. 427-436.

Warnatz, J., Mass, U., and Dibble, R. W., 2006, Combustion, 4th Edition, Springer.

Westbrok, C. K., and Drier, C. K., 1981, Simplified Reaction Mechanisms for the Oxidation of Hydrocarbon Fuels in Flames, Combustion Science and Technology, Vol. 27, pp. 31-46.

Wilcox, D. C., 1988, Reassessment of the ScaleDetermining Equation for Advenced Turbulence Models, AIAA Journal, Vol. 26, pp. 1299-1310.

Vascellari, M., and Cau, G., 2012, Influence of Turbulence-Chemical Interaction on CFD Pulverized coal MILD Combustion Modeling, Fuel, Vol. 101, pp. $90-101$.

Xu, M., Azevedo, J. L. T., and Carvalho, M. G., 2000, Modelling of the Combustion Process and NOx Emission in a Utility Boiler, Fuel, Vol. 79, pp. 16111619.

Yeh, C. P., Du, S. W., Tsai, C. H., and Yang, R. J., 2012, Numerical Analysis of Flow and Combustion Behavior in Tuyere and Racewayof Blast Furnace Fueled with Pulverized Coal and Recycled Top Gas, Energy, Vol. 42, pp. 233-240. 